\title{
Assessment of the Inhibition Efficiency of 3-amino-5-methylthio- 1H-1,2,4-triazole Against the Corrosion of Mild Steel in Acid Chloride Solution
}

\author{
Mieczyslaw Scendo , Katarzyna Staszewska-Samson \\ Institute of Chemistry, Jan Kochanowski University in Kielce, Swietokrzyska 15G, PL- 25406 Kielce, \\ Poland \\ *E mail: scendo@ujk.edu.pl
}

doi: $10.20964 / 2017.06 .86$

Received: 13 March 2017 / Accepted: 29 April 2017 / Published: 12 May 2017

\begin{abstract}
Influence of 3-amino-5-methylthio-1H-1,2,4-triazole (AMTTA) concentration on the corrosion of C45 mild steel in acid chloride solutions were studied. The potentiodynamic (PD) polarization, electrochemical impedance spectroscopy (EIS) methods and quantum chemical calculations were used. The surface morphology of specimens were observed through inverted metallographic microscope (IMM). It has been shown that the inhibition efficiency increased with an increase in the concentration of 3-amino-5-methylthio-1H-1,2,4-triazole. Tafel polarization study revealed that AMTTA acted as mixed type inhibitor. The best fit to the experimental data was obtained using Temkin adsorption isotherm. It was found that the adsorption of inhibitor on the mild steel surface takes place through a typical physisorption. Moreover, the adsorption mechanism of AMTTA on C45 mild steel surface was proposed and discussed.
\end{abstract}

Keywords: A. C45 mild steel; A. 3-amino-5-methylthio-1H-1,2,4-triazole; C. Inhibition efficiency; C. Corrosion rate; $\mathrm{C}$. Temkin adsorption isotherm

\section{$\underline{\text { FULL TEXT }}$}

(C) 2017 The Authors. Published by ESG (www.electrochemsci.org). This article is an open access article distributed under the terms and conditions of the Creative Commons Attribution license (http://creativecommons.org/licenses/by/4.0/). 